\title{
Transport and Metabolism of Pyridoxine and Pyridoxal in Mice
}

\author{
Tae SAKURAI, Tadashi AsAKURA, and Makoto MATSUDA ${ }^{1}$ \\ Department of Biochemistry, The Jikei University School of Medicine, \\ Nishi-shinbashi, Minato-ku, Tokyo 105, Japan
}

(Received July 2, 1986)

\begin{abstract}
Summary $\quad\left[{ }^{3} \mathrm{H}\right]$ Pyridoxine or $\left[{ }^{3} \mathrm{H}\right]$ pyridoxal in physiological amounts was orally administered to mice and the distribution of isotope between the six recognized forms of vitamin $\mathbf{B}_{6}$ and pyridoxic acid was determined at different times after the administration in the intestine, liver, blood, and brain. After $7 \mathrm{~min}$ about $50 \%$ of the radioactivity in pyridoxine and pyridoxal had been absorbed by the intestine and transported to the blood and other organs. When $\left[{ }^{3} \mathrm{H}\right]$ pyridoxine was administered, labeled pyridoxal, pyridoxal- and pyridoxine-phosphate were found in the intestine and liver, and labeled pyridoxine could not be detected in the peripheral blood but substantial amounts of labeled pyridoxal and pyridoxalphosphate were found in the blood. The time course of the blood $\left[{ }^{3} \mathrm{H}\right]$ pyridoxal levels following the administration of $\left[{ }^{3} \mathrm{H}\right]$ pyridoxine was similar to that following the administration of $\left[{ }^{3} \mathrm{H}\right]$ pyridoxal. These results suggest that the intestine and/or liver play a major role. in converting dietary pyridoxine to circulating pyridoxal which is taken up and phosphorylated by other organs. Moreover, most of the blood $\left[{ }^{3} \mathrm{H}\right]$ pyridoxal was shown to be located in the plasma. This localization may facilitate utilization by the organs.
\end{abstract}

Key Words pyridoxine, pyridoxal, pyridoxal phosphate, intestine, liver

Of the six forms of vitamin $\mathrm{B}_{6}$, pyridoxine (PN), pyridoxal (PL), pyridoxamine (PM) and their phosphorylated forms (PNP, PLP, and PMP), PLP and PMP, the coenzyme forms, are the major $\mathrm{B}_{6}$ compounds in tissues $(1)$. PN is the form of $\mathrm{B}_{6}$ found in foods from plant sources (2) and is the form most commonly used in vitamin supplements. Therefore, the transport and metabolism of PN to the active coenzyme in the various organs and tissues are important elements in the management of this nutrient.

The general pathway for the metabolic interconversion of $\mathrm{B}_{6}$ vitamers is well

${ }^{1}$ 桜井多恵, 朝倉 正, 松田 誠 
known. PN is phosphorylated to PNP by PL kinase which has been detected in all mammalian tissues investigated (3). PNP is converted to PLP by PNP oxidase (4) which, in contrast to the wide distribution of PL kinase, is confined to a few tissues $(5,6)$. The highest activity of PNP oxidase is found in the liver and intestine with only limited activity in the brain and kidney, but almost no activity in the lung, heart, muscle and pancreas. PLP can be converted to PMP by enzymatic transamination or to PL by hydrolysis with phosphatases (7). PL is then converted to pyridoxic acid by PL oxidase (6) or again to PLP by PL kinase.

Results from studies of perfused intestine and liver indicate that PN is rapidly taken up by these cells, phosphorylated to PNP by PL kinase and then converted to PLP by PNP oxidase $(8,9)$. These two enzymes plus phosphatases provide a means of converting dietary PN to PL. In fact, it was found that the PLP newly formed in perfused liver (9) or in isolated hepatocytes (10) was converted to PL and released into the perfusate or the medium. These results suggest that when PN is given as dietary $\mathrm{B}_{6}$, PN may be converted to circulating PL, and the PL may be used as an important source of $\mathrm{B}_{6}$ for most tissues and organs. Further evidence that PL has a transport role was provided by the observation that human plasma PL levels significantly increased in response to PN supplementation(10).

The availability of $\left[{ }^{3} \mathrm{H}\right] \mathrm{B}_{6}$ vitamers with high specific activity has permitted several experiments that have clarified the processes of transport and metabolism of $\mathrm{B}_{6}$ vitamers in perfused organs $(8,9,11-13)$. In this study, a physiological amount of $\left[{ }^{3} \mathrm{H}\right] \mathrm{PN}$ and $\left[{ }^{3} \mathrm{H}\right] \mathrm{PL}$ with a high specific activity was orally administered to mice, and the distribution of isotope among $\mathrm{B}_{6}$ vitamers in various organs including blood was determined to investigate the processes of the transport and metabolism of the vitamers in a whole animal.

\section{MATERIALS AND METHODS}

Chemicals. $\left[{ }^{3} \mathrm{H}\right] \mathrm{PN}$ was obtained from the Radiochemical Centre (Amersham, England) with a specific activity of about $1.4 \mathrm{Ci} / \mathrm{mmol}$. Purification was performed with a Amberlite column (14). $\left[{ }^{3} \mathrm{H}\right] \mathrm{PL}$ was prepared from $\left[{ }^{3} \mathrm{H}\right] \mathrm{PN}$ by oxidation with manganese dioxide as described by Viscontini et al.(15). Acid phosphatase was purchased from Sigma Chemical Co.

Animals and tissue preparation. DDY, male mice (4 weeks old) were utilized as experimental animals. Food was withheld from the animals for $6 \mathrm{~h}$ before the experiments. The animals were injected through a cannula into the gastric cavity with $100 \mu \mathrm{l}$ of saline solution of $\left[{ }^{3} \mathrm{H}\right] \mathrm{PN}$ or $\left[{ }^{3} \mathrm{H}\right] \mathrm{PL}$ (approx. $1.4 \mathrm{nmol}, 2 \mu \mathrm{Ci}$ ). The mice were decapitated at different times after the administration. The intestine, liver and brain were quickly removed, weighed and then homogenized in 9 volumes of $1 \mathrm{~N}$ perchloric acid, followed by centrifugation $(20,000 \times g, 15 \mathrm{~min})$. Blood removed from the heart was also homogenized in 9 volumes of $1 \mathrm{~N}$ perchloric acid and centrifuged. The precipitate was washed once with $0.2 \mathrm{~N}$ perchloric acid and all supernatants were combined. The combined supernatant was neutralized with $5 \mathrm{~N}$ 
$\mathrm{KOH}$ to $\mathrm{pH} 3-4$, and centrifuged at $20,000 \times g$ for $15 \mathrm{~min}$. In some cases, blood was mixed with EDTA (a few $\mathrm{mg}$ ) and centrifuged at $3,000 \times g$ for $5 \mathrm{~min}$ to separate plasma and erythrocytes, which were extracted with perchloric acid as described here.

Chromatographic procedures. $\quad \mathrm{B}_{6}$ vitamers were separated into fractions by the chromatographic procedures described by Loo and Badger with some modification (14). The extracts.were quantitatively transferred to an Amberlite CG-120 column $(0.4 \times 1.75 \mathrm{~cm})$ equilibrated in $0.1 \mathrm{M}$ acetate buffer $(\mathrm{pH} 4)$ and washed through the column with $1.5 \mathrm{ml}$ of the same buffer. The first effluent, containing PLP, PNP, PMP and pyridoxic acid, was collected in one fraction and kept to separate further into each component. The column was sequentially washed to elute the nonphosphorylated $\mathrm{B}_{6}$ vitamers as follows: $\mathrm{PL}, 1.2 \mathrm{ml}$ of $0.1 \mathrm{M} \mathrm{Na}$ phosphate buffer (pH 6.0) after $1.0 \mathrm{ml}$ of $0.1 \mathrm{M}$ acetate buffer ( $\mathrm{pH} 5.0$ ); $\mathrm{PN}, 2.0 \mathrm{ml}$ of $0.1 \mathrm{M} \mathrm{Na}$ phosphate buffer ( $\mathrm{pH} 6.5$ ); and $\mathrm{PM}, 1.5 \mathrm{ml}$ of $0.1 \mathrm{M} \mathrm{Na}$ phosphate buffer $(\mathrm{pH} 8.5)$. The first effluent was adjusted to $\mathrm{pH} 5$ with $5 \mathrm{~N} \mathrm{KOH}$, and treated with acid phosphatase $\left(0.5 \mathrm{mg} / \mathrm{ml}\right.$, incubation for $60 \mathrm{~min}$ at $\left.37^{\circ} \mathrm{C}\right)$ to hydrolyze PLP, PNP, and PMP to PL, PN, and PM, respectively. The treated solution was adjusted to $\mathrm{pH}$ 3-4 with acetic acid and again applied to the same Amberlite column as above. Pyridoxic acid was eluted with $1.5 \mathrm{ml}$ of $0.1 \mathrm{M}$ acetate buffer $(\mathrm{pH} 4)$, and PL, PN, and PM derived, respectively, from PLP, PNP, and PMP were sequentially eluted in the same manner as described above.

In some cases, the first effluent containing PLP, PNP, PMP and pyridoxic acid was applied to a $0.4 \times 3.5-\mathrm{cm}$ Dowex $1 \times 8$ (formate-type) column equilibrated in $0.05 \mathrm{M} \mathrm{K}$ formate buffer ( $\mathrm{pH} 4.25)$. Elution was performed with a continuous gradient from $0.05 \mathrm{M}$ potassium formate $(\mathrm{pH} 4.25)$ to $0.05 \mathrm{M}$ potassium citrate plus $0.2 \mathrm{M}$ potassium chloride ( $\mathrm{pH} 4.25$ ), as described by Bain and Williams (16). $\mathrm{B}_{6}$ vitamers were well resolved and came off the column in the order of PMP, PNP, PLP, and pyridoxic acid.

Isotope determination. Radioactive assays were carried out on the column fractions using a liquid scintillation spectrometer. Aliquots of $2 \mathrm{ml}$ were added to $4.5 \mathrm{ml}$ of a scintillator ACS II.

\section{RESULTS}

The absorption of $\left[{ }^{3} \mathrm{H}\right] \mathrm{PN}$ by the intestine and the distribution of ${ }^{3} \mathrm{H}$ among $\mathrm{B}_{6}$ vitamers in the organ as a function of time are presented in Fig. 1a. At 7 min after the oral administration of $\left[{ }^{3} \mathrm{H}\right] \mathrm{PN}$ about half of the isotope in the intestine was absorbed, and labeled PNP, PLP, and PL started to appear in the organ. The amounts of labeled PMP and PM were small as compared with labeled PLP and PL (data not shown).

The distribution of ${ }^{3} \mathrm{H}$ among the $\mathrm{B}_{6}$ vitamers in the liver as a function of time after the $\left[{ }^{3} \mathrm{H}\right] \mathrm{PN}$ administration is illustrated in Fig. 1b. The greater part of the isotope in the liver was phosphorylated to PLP and a small amount to PNP. A 

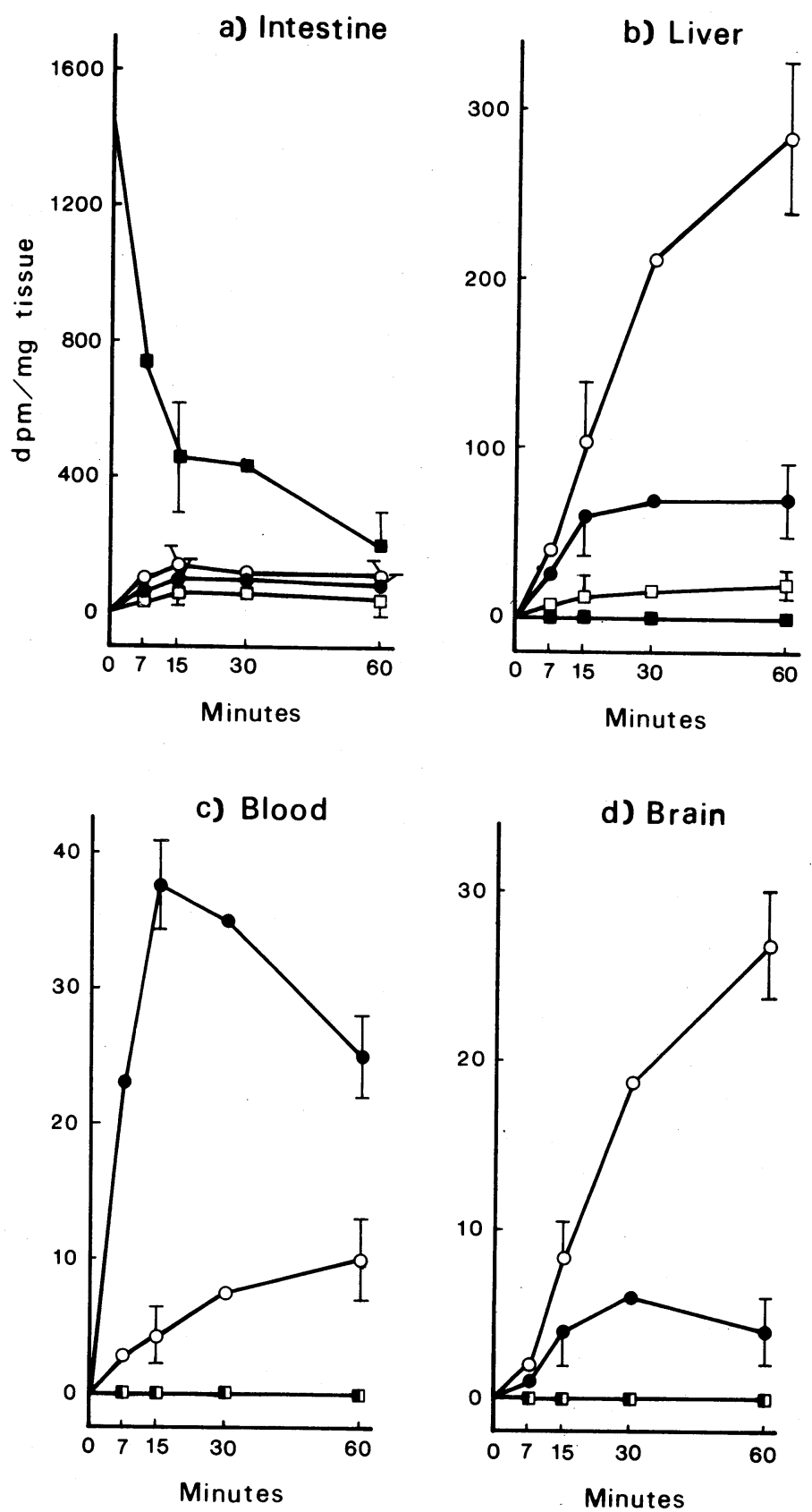

Fig. 1. Distribution of ${ }^{3} \mathrm{H}$ in $\mathrm{B}_{6}$ vitamers in mouse tissues after oral administration of $\left[{ }^{3} \mathrm{H}\right]$ pyridoxine $(2 \mu \mathrm{Ci})$. Pyridoxine $(\boldsymbol{\square})$, pyridoxine phosphate $(\square)$, pyridoxal $(\mathbf{0})$ and pyridoxal phosphate $(O)$. Symbols indicate means $\pm \operatorname{SD}(n=3)$. Values at time 0 were plotted as expected values. 
considerable amount of $\left[{ }^{3} \mathrm{H}\right] \mathrm{PL}$ was found in the liver in the $7 \mathrm{~min}$ following the administration, whereas $\left[{ }^{3} \mathrm{H}\right] \mathrm{PN}$ was not found in the organ during the period, in spite of continuous absorption of $\left[{ }^{3} \mathrm{H}\right] \mathrm{PN}$ by the intestine. Labeled PMP and PM were present in small amounts as compared with labeled PLP, PL, and PNP.

Figure 1c shows the distribution of ${ }^{3} \mathrm{H}$ in $\mathrm{B}_{6}$ vitamers in the blood as a function of time after the $\left[{ }^{3} \mathrm{H}\right] \mathrm{PN}$ administration. In contrast to the distribution in the liver, the isotope in the blood was first in PL and secondly in PLP, and was not in PNP and PN. Labeled PL rapidly reached a maximum level after $15 \mathrm{~min}$ and then diminished somewhat gradually. Most labeled PL in the blood was located in the plasma while about half of labeled PLP was located in the blood cells (Fig. 2a). Labeled PMP and PM were scarcely found in either the plasma or blood cells.

Figure 1d shows the distribution of ${ }^{3} \mathrm{H}$ in $\mathrm{B}_{6}$ vitamers in the brain as a function of time after the $\left[{ }^{3} \mathrm{H}\right] \mathrm{PN}$ administration. The isotope in the brain was found first in PLP and secondly in PL, and was not found in PNP and PN. Labeled PMP and PM were only found in small amounts as compared with labeled PLP and PL.

The absorption of $\left[{ }^{3} \mathrm{H}\right] \mathrm{PL}$ from the intestine and the distribution of ${ }^{3} \mathrm{H}$ in $\mathrm{B}_{6}$ vitamers in various organs as function of time are presented in Fig. 3a-d. At 7 min after the oral administration of $\left[{ }^{3} \mathrm{H}\right] \mathrm{PL}$, about half of the isotope administered was absorbed, and labeled $\mathrm{B}_{6}$ vitamers started to appear in the organs. The administered $\left[{ }^{3} \mathrm{H}\right] \mathrm{PL}$ accumulated in the liver, blood and brain, in marked contrast to the case of
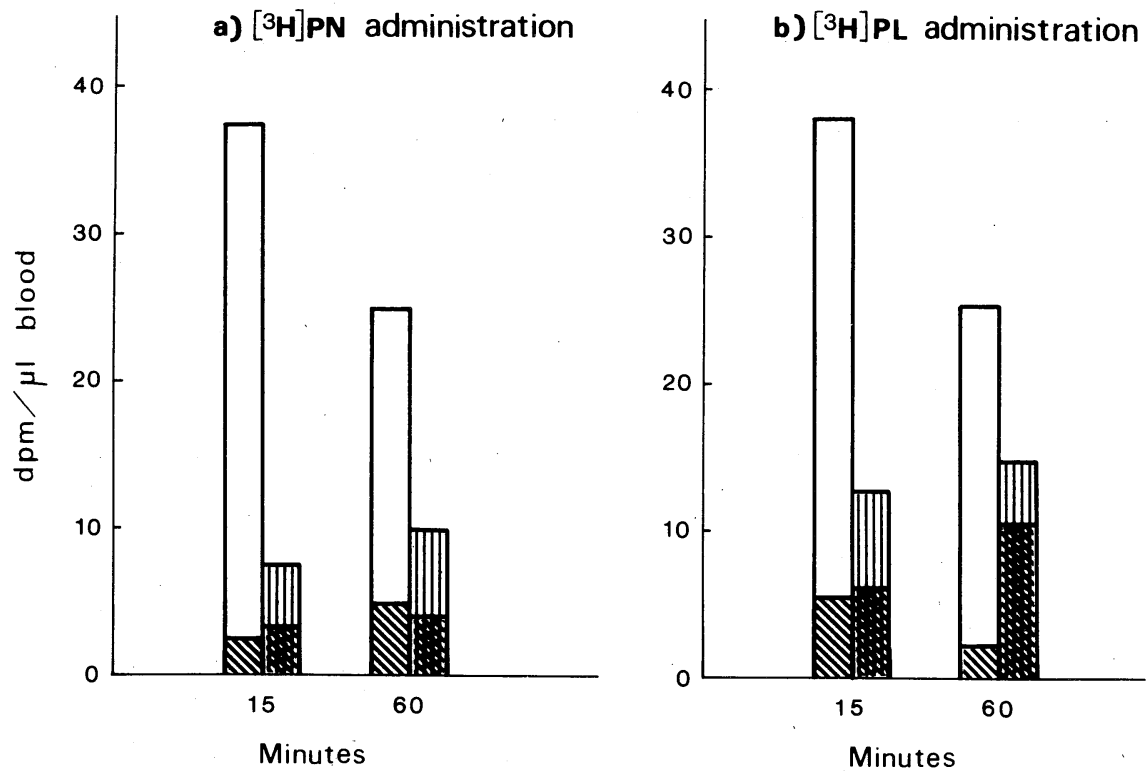

Fig. 2. Distribution of $\left[{ }^{3} \mathrm{H}\right]$ pyridoxal and $\left[{ }^{3} \mathrm{H}\right]$ pyridoxal phosphate in blood plasma and blood cells 15 and $60 \mathrm{~min}$ after oral administration of $\left[{ }^{3} \mathrm{H}\right]$ pyridoxine (a) and of $\left[{ }^{3} \mathrm{H}\right]$ pyridoxal (b). $\square,\left[{ }^{3} \mathrm{H}\right]$ pyridoxal in plasma; $\mathbb{\mathbb { N }}$, in cells; 血, $\left[{ }^{3} \mathrm{H}\right]$ pyridoxal phosphate in plasma; and in cells. 

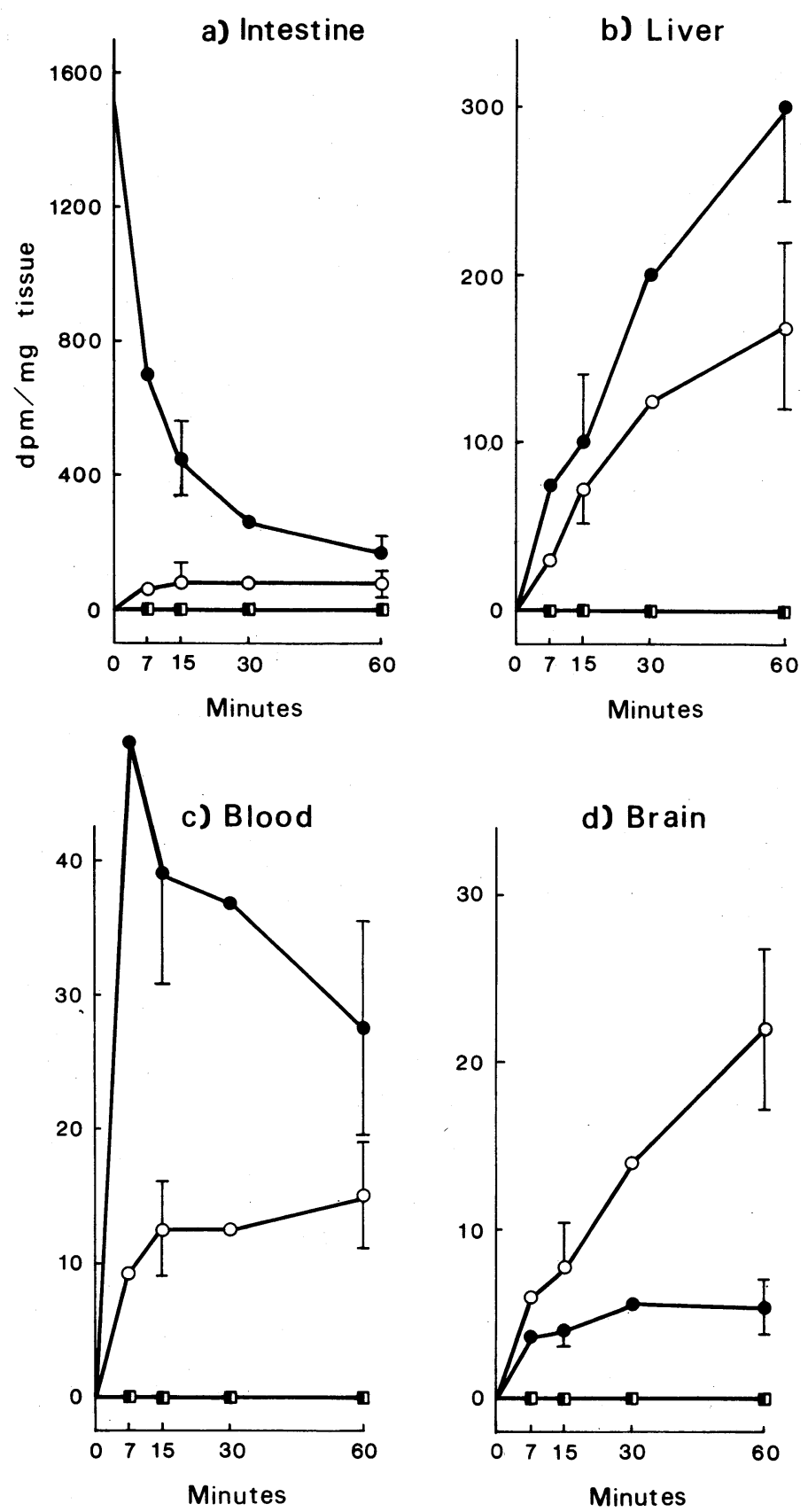

Fig. 3. Distribution of ${ }^{3} \mathrm{H}$ in $\mathrm{B}_{6}$ vitamers in mouse tissues after oral administration of $\left[{ }^{3} \mathrm{H}\right]$ pyridoxal $(2 \mu \mathrm{Ci})$. Pyridoxine (ם), pyridoxine phosphate $(\square)$, pyridoxal $(\bullet)$ and pyridoxal phosphate $(O)$. Symbols indicate means $\pm \operatorname{SD}(n=3)$. Values at time 0 were plotted as expected values. 
$\left[{ }^{3} \mathrm{H}\right] \mathrm{PN}$ in which the administered $\left[{ }^{3} \mathrm{H}\right] \mathrm{PN}$ did not appear at all in these organs. Production of $\left[{ }^{3} \mathrm{H}\right] \mathrm{PLP}$ from $\left[{ }^{3} \mathrm{H}\right] \mathrm{PL}$ in the organs was not so different from that when $\left[{ }^{3} \mathrm{H}\right] \mathrm{PN}$ was administered. Tritium in the organs was not in PN as well as in PNP, which was found in small amounts in the intestine and liver when $\left[{ }^{3} \mathrm{H}\right] \mathrm{PN}$ was administered. Most labeled PL in the blood was located in the plasma while about half of labeled PLP was located in the blood cells (Fig. 2b). Labeled PMP and PM were only found in small amounts as compared with labeled PLP and PL.

No significant amount of labeled pyridoxic acid was found in the tissues tested following $\left[{ }^{3} \mathrm{H}\right] \mathrm{PN}$ or $\left[{ }^{3} \mathrm{H}\right] \mathrm{PL}$ administration.

\section{DISCUSSION}

In a study on vitamin $B_{6}$ metabolism in animals, it is desirable to administer $B_{6}$ vitamers with a high specific radioactivity in "trace" amounts to achieve a physiological steady state. The $\left[{ }^{3} \mathrm{H}\right] \mathrm{PN}$ and $\left[{ }^{3} \mathrm{H}\right] \mathrm{PL}$ used in this study had a high specific activity suitable for this purpose.

The present experiment shows that although $\left[{ }^{3} \mathrm{H}\right] \mathrm{PN}$ is rapidly absorbed across the intestinal wall, $\left[{ }^{3} \mathrm{H}\right] \mathrm{PN}$ cannot be found in the circulatory blood. Instead of $\left[{ }^{3} \mathrm{H}\right] \mathrm{PN}$ a noticeable amount of $\left[{ }^{3} \mathrm{H}\right] \mathrm{PL}$ appeared rapidly in the blood (Fig. 1c). These results suggest that PN is completely taken up by the intestine and liver and converted there to $\mathrm{PL}$, and then the product $\mathrm{PL}$ is released into the circulatory blood. In fact the isotope of $\left[{ }^{3} \mathrm{H}\right] \mathrm{PN}$ appeared in PNP, PLP, and PL in the intestine and liver following the $\left[{ }^{3} \mathrm{H}\right] \mathrm{PN}$ administration, suggesting that $\left[{ }^{3} \mathrm{H}\right] \mathrm{PL}$ was synthesized from $\left[{ }^{3} \mathrm{H}\right] \mathrm{PN}$ through the PN-PNP-PLP-PL pathway. It has been reported that intestine and liver cells exhibit high levels of activity of PL kinase, PNP oxidase and phosphatase $(8,9,17)$.

Results from studies of perfused liver(9) or isolated hepatocytes (10) have indicated that PN is rapidly taken up by these cells, converted to PL and then significantly released into the perfusate or the medium. The releases of PL observed in these in vitro experiments seem to reflect the release of PL into the circulatory blood shown in the present experiment. The intestine and liver may provide a means of completely converting dietary PN to circulating PL, which can then serve as a source of the coenzyme PLP in all tissues that contain PL kinase, whether they contain PNP oxidase or not. The results shown in the present report and the observation that human plasma PL levels can markedly increase in response to PN supplementation(10) suggest that in a physiological state PL may have an important transport role between most organs and may be the major source of PLP for these cells. $\left[{ }^{3} \mathrm{H}\right] \mathrm{PLP}$ found in the brain (Fig. 1d), therefore, is considered to come from $\left[{ }^{3} \mathrm{H}\right] \mathrm{PL}$ in the blood.

The levels of $\left[{ }^{3} \mathrm{H}\right] \mathrm{PL}$ in the peripheral blood and its time course following the administration of $\left[{ }^{3} \mathrm{H}\right] \mathrm{PN}$ (Fig. 1c) was similar to those following the administration of the same dose of $\left[{ }^{3} \mathrm{H}\right] \mathrm{PL}$ (Fig. 3c). This result suggests that the intestine and liver can very rapidly and efficiently convert dietary PL to circulating PL. That the 


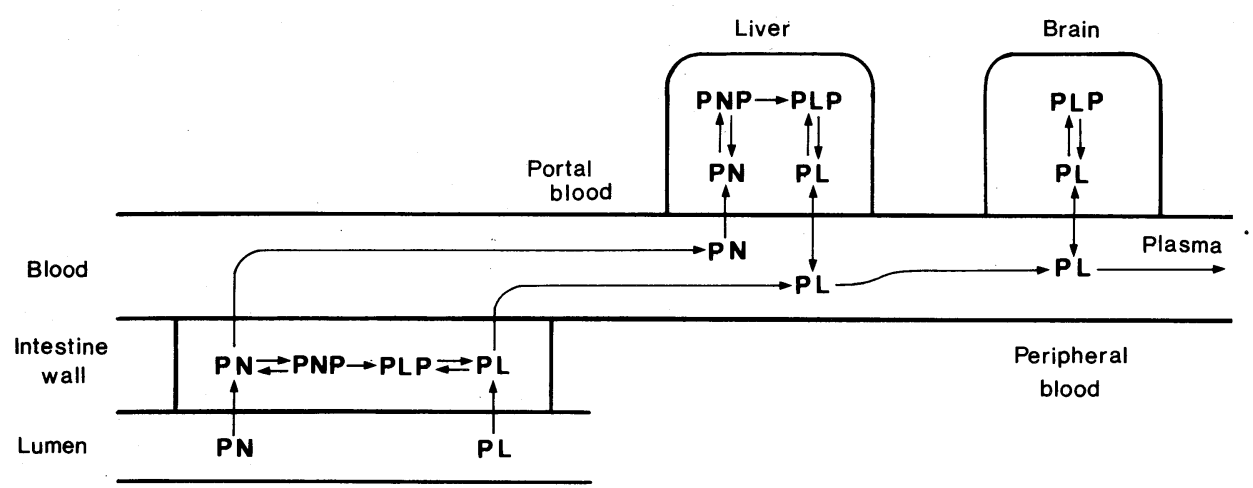

Fig. 4. Metabolic transformations of pyridoxine and pyridoxal by the intestine, liver and brain, and suggested role of the liver and intestine as a source of pyridoxal for the brain and other organs. PN, pyridoxine; PNP, pyridoxine phosphate; PL, pyridoxal; PLP, pyridoxal phosphate.

quantity of $\left[{ }^{3} \mathrm{H}\right] \mathrm{PLP}$ found in the brain following the $\left[{ }^{3} \mathrm{H}\right] \mathrm{PN}$ administration is similar to that following the $\left[{ }^{3} \mathrm{H}\right] \mathrm{PL}$ administration (Figs. $1 \mathrm{~d}$ and $3 \mathrm{~d}$ ) is possibly due to a similar concentration of blood $\left[{ }^{3} \mathrm{H}\right] \mathrm{PL}$ in both cases.

The observation that most $\left[{ }^{3} \mathrm{H}\right] \mathrm{PL}$ in the blood is located in the plasma (Fig. 2) suggests that plasma PL may be the major source of PLP for most tissues and that the loose binding of PL to plasma albumin (18) and the resulting accumulation of this vitamer in the plasma may provide a means for PL to function as a principal transport form in the blood (Fig. 4).

In any case, it is important to note that when a physiological level of PN is orally administered to mice, no PN reaches the circulating system, but PL appears as the predominant form in the circulating blood. In this condition, therefore, all other organs than the intestine and liver are thought not to obtain PN but to obtain PL from the plasma and then to convert it to PLP via PL kinase. Whether [ $\left.{ }^{3} \mathrm{H}\right] \mathrm{PL}$ found in the blood originated in the intestine or in the liver remains to be clarified in future experiments. We are now proceeding with analyses of $\left[{ }^{3} \mathrm{H}\right] \mathrm{B}_{6}$ vitamers in portal blood following $\left[{ }^{3} \mathrm{H}\right] \mathrm{PN}$ administration in order to solve this problem (Fig. 4).

It should be noted that no significant amount of labeled pyridoxic acid is found in the tissues following not only $\left[{ }^{3} \mathrm{H}\right] \mathrm{PN}$ but also $\left[{ }^{3} \mathrm{H}\right] \mathrm{PL}$ administration. A possible explanation for this result might be that pyridoxic acid produced in the tissues does not remain there but is rapidly transported into urine. Assay of labeled $B_{6}$ vitamers excreted into urine is now in progress.

\section{REFERENCES}

1) Lyon, J. B., Jr., Bain, J. A., and Williams, H. L. (1962): The distribution of vitamin B $_{6}$ 
in the tissues of two inbred strains of mice fed complete and vitamin $\mathbf{B}_{6}$-deficient rations. J. Biol. Chem., 237, 1989-1991.

2) Rabinowitz, J. C., and Snell, E. E. (1948): The vitamin B group. XIV. Distribution of pyridoxal, pyridoxamine, and pyridoxine in some natural products. J. Biol. Chem., 176, 1157-1167.

3) McCormick, D. B., Gregory, M. E., and Snell, E. E. (1961): Pyridoxal phosphokinases. I. Assay, distribution, purification, and properties. J. Biol. Chem., 236, 2076-2084.

4) Wada, H., and Snell, E. E. (1961): The enzymatic oxidation of pyridoxine and pyridoxamine phosphate. J. Biol. Chem., 236, 2089-2095.

5) Pogell, B. M. (1958): Enzymatic oxidation of pyridoxamine phosphate to pyridoxal phosphate in rabbit liver. J. Biol. Chem.; 232, 761-776.

6) Morisue, T., Morino, Y., Sakamoto, Y., and Ichihara, K. (1960): Enzymatic studies on pyridoxine metabolism. III. Pyridoxine phosphate oxidase. J. Biochem., 48, 28-36.

7) Turner, J. M. (1961): Pyridoxal phosphate breakdown by an alkaline-phosphate preparation. Biochem. J., 80, 663-668.

8) Buss, D. D., Hamm, M. W., Mehansho, H., and Henderson, L. M. (1980): Transport and metabolism of pyridoxine in the perfused small intestine and the hind limb of the rat. J. Nutr., 110, 1655-1663.

9) Mehansho, H., Buss, D. D., Hamm, M. W., and Henderson, V. M. (1980): Transport and metabolism of pyridoxine in rat liver. Biochim. Biophys. Acta, 631, 112-123.

10) Lumeng, L., Lui, A., and Li, T.-K. (1980): Plasma content of $B_{6}$ vitamers and its relationship to hepatic vitamin $\mathrm{B}_{6}$ metabolism. J. Clin. Invest., 66, 688-695.

11) Mehansho, H., Hamm, M. W., and Henderson, L. M. (1979): Transport and metabolism of pyridoxal and pyridoxal phosphate in the small intestine of the rat. $J$. Nutr., 109, 1542-1551.

12) Hamm; M. W., Mehansho, H., and Henderson, L. M. (1979): Transport and metabolism of pyridoxamine and pyridoxamine phosphate in the small intestine of the rat. J. Nutr., 109, 1552-1559.

13) Hamm, M. W., Mehansho, H., and Henderson, L. M. (1980): Management of pyridoxine and pyridoxal in the isolated kidney of the rat. J. Nutr., 110, 1597-1609.

14) Loo, Y. H., and Badger, L. (1969): Spectrofluorimetric assay of vitamin $B_{6}$ analogues in brain tissue. J. Neurochem., 16, 801-804.

15) Viscontini, M., Ebnother, C., and Karrer, P. (1951): Konstitution und shynthese der codecarboxylase. Helvetica Chimica Acta, 34, 1834-1842.

16) Bain, J. A., and Williams, H. L. (1960): Concentrations of $B_{6}$ vitamers in tissues and tissue fluids, in Inhibition of the Nervous System and Gamma-Aminobutyric Acid, ed. by Roberts, E., Baxter, C. F., Harreveld, A. V., Wiersma, C. A. G., Adey, W. R., and Killam, K. F., Pergamon Press, New York, pp. 275-293.

17) Li, T.-K., Lumeng, L., and Veitch, R. L. (1974): Regulation of pyridoxal 5'-phosphate metabolism in liver. Biochem. Biophys. Res. Commun., 61, 677-684.

18) Anderson, B. B., Newmark, P. A., Rawlins, M., and Green, R. (1974): Plasma binding of vitamin $\mathrm{B}_{6}$ compounds. Nature, 250, 502-504. 